or era of good feeling collapsing in 1859 when Darwin published the Origin of Species, and not merely two but a whole series of cultures emerged, each with its own experts, or professionals, and tests of truth. This is interesting, and may be true; but if so, it would only show that events in England moved more slowly than they had in France or Germany, where the process had begun much earlier. One may also suspect that a focus on her Cambridge men-a group dedicated to the unity of knowledge-makes one attribute too much importance to them, and especially to Darwin, who appears here as the only star of any magnitude in the life sciences; Huxley comes in as his accompanist, rather than as the introducer of the revolutionary new physi-

\section{Foster's school}

\section{R. K. French}

Michael Foster and the Cambridge School of Physiology: The Scientific Enterprise in Late Victorian Society. By G. L. Geison. Pp.401 (Princeton University Press; Princeton, New Jersey, 1978.) $£ 18.40$.

Here is a biography of Foster and an account of the Cambridge School of Physiology. It is not, as the subtitle suggests, about The Scientific Enterprise in Late Victorian Society as it is limited to "one small group of English physiologists . . between 1870 and 1900"' (preface).

Although we are not far removed in time from late Victorian science, there is still a great deal we do not know about some of it, including physiology: Geison's book is a step in the right direction. Modern fashions in history range from history of ideas to sociological history, and historians, if not the readers of historical books, look for more than the old-fashioned Life and Times biography. But only rarely have we enough information to make the most of both of these approaches.

The format of this book is determined partly by the demands of social history, but the book itself is something of a pilot study in an area which, as Geison insists, is still very little known. The result is that these modern historical tools cannot be used effectively, and the text gives the impression of being somewhat over-written, a little bit 'stretched'. Another reason for this is the book's origin as a dissertation.

The copious text is subdivided by elaborate headings, which suggest a i ology from the Continent. In the decade before 1859 , religious doubt had spread widely in Britain, and novels describing it had become a genre; men such as Frank Newman and J. A. Froude were prominent agnostics owing little or nothing to Darwin or his circle.

One may suspect then that some of Dr Cannon's generalisations apply not far beyond the limits of her "network"; but like the professionals she describes, she poses questions that will set others thinking for some time (and indeed have already done so) and she makes methodological remarks of great value to anybody interested in the history of science.

David Knight is Senior Lecturer in the History of Science at the University of Durham, UK.

somewhat laboured reworking of the material. The reader might even be well advised to read first the "Concluding Reflections" which so lucidly and tersely tie together the strands of the book that they are an indispensable guide to the detail and documentation of the earlier pages. These are naturally more exploratory than books written later in life. In his exploration Geison has uncovered a problem with Foster and has made valuable progress in seeing how it is answerable. Foster's reputation is that of a man with great influence on his subject and at the centre of its institutionalisation, yet the further the evidence and explanations for this are pursued the more elusive they become. Perhaps this problem can be historically generalised as the 'Boerhaave problem'. Boerhaave was one of the most renowned medical teachers of all time, yet the reasons for his influence are difficult to pin down. He made no major discovery and his teaching contained few innovations. His successful synthesis of current systems must be part of the answer, but the resultant bland and conservative doctrine does not convince even the historian of ideas that it was the complete answer. Such a historian is compelled to use other techniques.

Geison's problematic Foster faded early as a research physiologist without having produced "a signal piece of research of the first order", and as the quotations prefixed to Geison's introduction show, neither contemporary or later historical opinion could in any concrete terms explain Foster's influence even by reference to his teaching. So, even though the problem calls for new historical techniques, the evidence is insufficient for their use. Geison's attempt to use them is dutiful but not always productive; at one point he is "ready to give up in despair" (p143) in attempting to solve the "mystery of Foster's achievement [which] can never be entirely dispelled"'(p188). In attempting to dispel it Geison very usefully investigates Foster's work on the myogenic origin of the heartbeat, his characteristically English evolutionary view of physiology, which form a strong 'history-of-ideas' theme for the book, and his tactics to promote his 'school'-for example his publication of his student's papers. Much more hypothetical is Geison's brief and flirtatory parallel between on the one hand the politics of Bismarckian Germany, Czarist Russia, and the neurogenic 'autocratic' theory of heartbeat, and on the other, the opposing, innate, non-centralised 'democratic' myogenic theory, and Foster's role therein.

Readers of Nature will probably find these remarks too carping, and will certainly find the book itself a very welcome piece of work, carefully researched, dealing with an important topic and necessarily interesting to modern scientists and historians.

R. K. French is Director of the Wellcome Unit for the History of Medicine, University of Cambridge, UK.

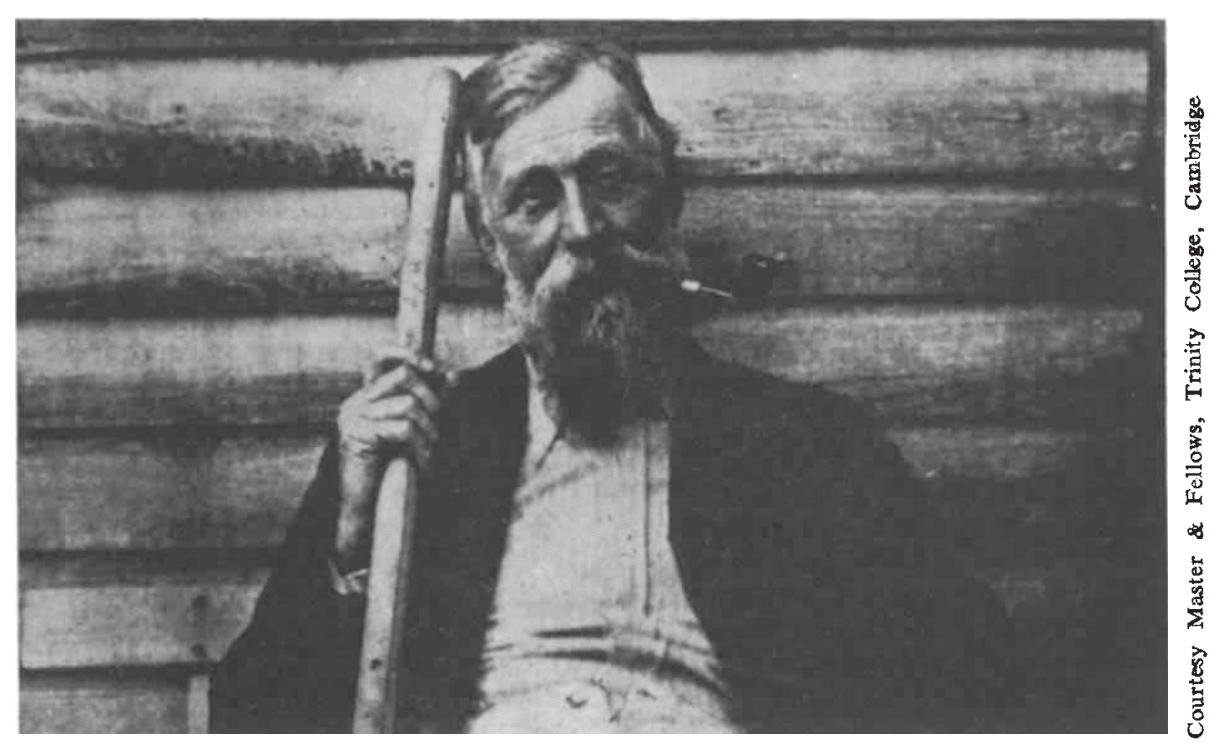

